\title{
A PROTEÇÃO DOS DESLOCADOS AMBIENTAIS NO REGIME INTERNACIONAL DOS REFUGIADOS
}

\author{
Andrea Pacheco Pacífico* \\ Marina Ribeiro Barboza Gaudêncio*
}

O deslocamento de pessoas por causas ambientais gera discussões pela ausência de reconhecimento legal e proteção jurídica específica para essa categoria de pessoas. Assim, este artigo examina o Regime Internacional dos Refugiados (RIR), conceitua deslocados ambientais (DA) e reflete sobre a ausência de proteção pelo RIR. Em seguida, examina as causas e as consequências dos deslocamentos e as formas de proteção aos DA, concluindo que os regimes vigentes não thes oferecem proteção efetiva. Uma solução, segundo Betts (2009), seria cooperação para proteção por persuasão via cruzamento de assuntos de interesse estatal, persuadindo Estados a cooperarem em seus interesses, como saída eficaz para a ausência de proteção efetiva aos DA.

Palavras-chave: deslocados ambientais, proteção internacional, Regime dos Refugiados.

\section{Do Regime internacional dos Refugiados}

A formação de regimes internacionais no mundo contemporâneo tem sido estabelecida por Estados e Organizações Internacionais. Krasner ${ }^{1}$ define regimes internacionais como "princípios [convicções de fato], normas [padrões de comportamento], regras [prescrições específicas para a ação] ou procedimentos de tomada de decisões [práticas para implementar escolha coletiva], implícitos ou explícitos, nos quais as expectativas dos atores convergem em uma determinada área de relações internacionais".

\footnotetext{
* Professora adjunta do curso de Relações Internacionais da UEPB e coordenadora do Núcleo de Estudo e Pesquisa sobre Deslocados Ambientais (NEPDA/UEPB). João Pessoa/Brasil.

** Bacharela em Direito no IESP e em Relações Internacionais na UEPB, membro do NEPDA/UEPB. João Pessoa/Brasil.

1 KRASNER, Stephen D. International Regimes, p. 2.
} 
Particularmente, com relação ao Regime Internacional dos Refugiados (RIR), segundo Betts², ele "representa o conjunto de normas, regras, princípios e procedimentos de tomada de decisão que regulam as respostas dos Estados à proteção dos refugiados". Assim, há o Alto Comissariado das Nações Unidas para os Refugiados (Acnur), criado em 1950, para proteger refugiados e outras categorias de pessoas, como solicitantes de refúgio, apátridas, retornados e alguns deslocados internos. Junto com ele, em 1951, foi aprovada a Convenção das Nações Unidas sobre o Estatuto dos Refugiados.

Em nível regional, os principais sistemas são o das Américas, o da União Europeia e o da África, que determinam individualmente procedimentos para solicitar refúgio e proteger refugiados em nível regional. Na África, a União Africana define refúgio na Convenção para Tratar dos Aspectos Específicos do Problema dos Refugiados na África (1969), cujo conceito de refúgio é mais abrangente que o da Convenção de 1951:

[o] 20 parágrafo do Artigo I da Convenção Africana estabelece que o termo "refugiado" também deve ser aplicado para todas as pessoas que, devido a agressões externas, ocupação, dominação estrangeira ou eventos que perturbem seriamente a ordem pública, em qualquer parte ou em todo o país de origem ou nacionalidade, são obrigadas a sair do seu lugar de residência habitual para procurar refúgio em outro lugar fora do seu país de origem ou nacionalidade.

Em nível de Américas, a Declaração de Cartagena sobre os Refugiados (1984) fornece uma definição ampliada de refugiado, em sua cláusula Terceira, considerando também refugiadas

[a]s pessoas que tenham fugido dos seus países porque sua vida, segurança ou liberdade tenha sido ameaçada pela violência generalizada, agressão estrangeira, conflitos internos, violação maciça dos direitos humanos ou outras circunstâncias que tenham perturbado gravemente a ordem pública.

Em terceiro, o Conselho da Europa criou a Convenção para a Proteção dos Direitos Humanos e das Liberdades Fundamentais (1950). Segundo o HREA ${ }^{3}$, "ela não contém nenhum direito específico ao solicitante de refúgio e nem faz nenhuma referência direta aos refugiados ou aos solicitantes de refúgio". Porém, a Corte Europeia de Direitos Humanos, no caso Soering versus Reino Unido (1989), estabeleceu que os Estados são de fato responsáveis, em certas circunstâncias, pelo bem-estar dos indivíduos em outros países ${ }^{4}$.

\footnotetext{
2 BETTS, Alexander. International Cooperation in the Global Refugee Regime, p. 5.

3 Human Rights Education Associates - HREA. Refugiados.

4 Ibidem.
} 
A Convenção de Genebra de 1951, em seu artigo $1^{\circ} \mathrm{A}$ (1), combinada com o Protocolo Adicional de Nova Yorque de 1967, define refugiado como todo aquele que,

receando com razão ser perseguido em virtude de raça, religião, nacionalidade, filiação em certo grupo social ou opiniões políticas, se encontra fora do país de nacionalidade e não pode ou, em virtude daquele receio, não quer pedir a proteção daquele país; ou que, se não tiver nacionalidade e estiver fora do país no qual tinha a sua residência habitual, não possa ou, em virtude do dito receio, a ele não queira voltar.

Como aponta Zanoni ${ }^{5}$, contudo, as causas de conflitos e deslocamentos forçados, que motivaram a criação do RIR, são diferentes no pós-guerra fria, ou seja, naquela época a preocupação global, em geral, era com conflitos políticos e ideológicos e atualmente a preocupação maior é com conflitos religiosos e étnicos, que culminam, por exemplo, em violação de direitos humanos, aumento das desigualdades entre os povos, problemas de saúde, violência e insegurança, como os conflitos causados pela escassez de recursos hídricos.

Ocorre que novos fatos excluem indivíduos da definição de refugiado do RIR, como ${ }^{6}$ a intensificação dos desastres naturais que causa destruição de casas que força o reassentamento; o aquecimento e a seca que causam destruição da produção agrícola, a redução das formas de subsistência e o acesso à água limpa; o aumento do nível do mar que causa os litorais impossíveis de serem habitados; e a competição sobre recursos naturais que causa conflitos que precipitam o deslocamento. Ou seja, há lacunas referentes à situação dos deslocados por questões ambientais, como degradação ambiental e mudanças climáticas.

\section{Dos deslocados ambientais}

Com as mudanças ocorridas no meio ambiente, pessoas se deslocam cada vez mais dentro do país ou alhures. Le Prestre ${ }^{7}$ ressalta que, no passado, estes indivíduos eram chamados de "refugiados econômicos ou vítimas da fome ou de desastres naturais". Por isso, conformea $\mathrm{OIM}^{8}$, nas últimas duas décadas, a comunidade internacional começou a se preocupar com as consequências da alteração ambiental para a mobilidade humana.

5 ZANONI, Anelise. Refugiados, apenas uma das denominações da crise global.

6 CASTLES, Stephen. Globalização, transnacionalismo e novos fluxos migratórios: Dos trabalhadores convidados às migrações globais; ZETTER, Roger, MORRIS, Tim e BOANO, Camillo. Environmentally Displaced People: Understanding the Linkages between Environmental change, livelihoods and forced migration; AGHAZARM, Christine e LACZKO, Frank. Migration, environment and climate change: assessing the evidence; LECKIE, Scott. Climate-related Disasters and Displacement: Homes for Lost Homes, Lands for Lost Lands, p. 119-132; HOMER-DIXON, T. On the threshold: environmental change as causes of violent conflict, p. 76-116.

LE PRESTRE, Philippe. Ecopolítica Internacional, p. 465.

8 OIM: International Organization for Migration. Migration, Climate Changes and Environment. 
Nesse sentido, surgem diferentes e preocupantes estimativas sobre a quantidade de deslocados ambientais no mundo, como Laczko e Aghazarm ${ }^{9}$, que apontam para um cenário de que nos próximos 40 anos haverá entre 25 milhões e um bilhão de pessoas deslocadas por mudanças climáticas.

Ademais, discute-se, hodiernamente, como os deslocados ambientais, que necessitam ir além das fronteiras do seu país, poderiam ser protegidos pelo RIR, mesmo havendo ausência de perseguição pelos motivos descritos na Convenção de 1951. Segundo Bates, o termo "refugiados ambientais" foi definido com precisão por El-Hinnawi ${ }^{10}$, em 1985, ao se referir aos indivíduos que fugiram de suas casas por mudança ambiental drástica o suficiente para tornar suas vidas ameaçadas ou insustentáveis, independentemente dos deslocados serem internos ou internacionais. Hens ${ }^{11}$ aponta definição mais recente de Myers, que reconhece como refugiado ambiental o que não possui vida segura, no local de origem, por causas ambientais incomuns, como "seca, desertificação, desmatamento, erosão do solo, escassez de água e mudança climática, além de catástrofes naturais como ciclones, tempestades e inundações".

O conceito de refugiado, conforme a Convenção de 1951, também não protege o deslocado ambiental. Para Zetter, apud Laczko e Aghazarm ${ }^{12}$, o termo "refugiado ambiental" é amplamente utilizado na mídia, mas essa categoria não existe à luz do direito internacional e, assim, corre o risco de minar a definição jurídica de refugiado e seu regime de proteção, além do fato de que a maioria dos deslocados ambientais são internos, fazendo mais sentido falar-se de deslocado interno ambiental, ao invés de refugiado, que é um termo transfronteiriço.

Ainda, a $\mathrm{OIM}^{13}$ usa o termo migrante ambiental para se referir às pessoas que migram, temporária ou permanentemente, no país ou no exterior, em virtude de "mudanças bruscas ou progressivas no ambiente" de modo a afetar negativamente suas vidas.

Nesta conceituação, os deslocados ambientais podem ser internos ou internacionais, temporários ou permanentes, podendo optar entre saírem do local de origem ou serem obrigados a deixá-lo, por ausência de meios de sobrevivência, e, por fim, eles não se deslocam somente devido a um evento ambiental, mas também por causa de conflitos políticos, econômicos ou sociais com ligação ambiental.

\footnotetext{
9 AGHAZARM, LACZKO, op. cit., p. 9.

${ }^{10}$ BATES, Diane C. Refugiados Ambientais? Classificando as Migrações Humanas Causadas pela Mudança Ambiental, p. 466.

11 HENS, Luc. Environmentally displaced people, p. 5.

12 AGHAZARM, LACZKO, op. cit., p. 18.

${ }^{13}$ OIM: International Organization for Migration. Discussion Note: Migration and the environment, p. 1.
} 
Os deslocados ambientais muitas vezes são confundidos com migrantes econômicos. Para Bingham ${ }^{14}$, muitos seres humanos se deslocam por perseguições, por conflitos, por necessidades econômicas ou por alteração no ambiente forte o suficiente para deixar a vida no local inviável, sendo, contudo, normalmente, reconhecidos como "migrantes econômicos" e inviabilizando, assim, a recepção de direitos específicos e de respostas adequadas relativas aos migrantes forçados.

Apesar de necessitarem de uma proteção internacional cada vez mais efetiva, os deslocados ambientais não possuem reconhecimento jurídico efetivo, embora, de acordo com o Acnur ${ }^{15}$, cada vez mais pessoas fogem de seu local de origem por razões diferentes das elencadas na Convenção dos Refugiados de 1951.

O RIR possui algumas lacunas que precisam ser preenchidas, pois a Convenção de 1951 não protege essa categoria de pessoas que sofre com eventos ambientais. Assim, o fator motivador dos deslocamentos ambientais não é um acontecimento isolado, pois eles necessitam migrar por uma multicausalidade de fatores ocorridos no meio ambiente, como políticos, econômicos, sociais, religiosos, culturais etc., embora o fator ambiental seja o preponderante.

\section{Das causas e das consequências do deslocamento ambiental}

As transformações ocorridas ao longo dos séculos, como a revolução tecnológica e os crescimentos populacionais, fizeram com que o meio ambiente sofresse alterações, não somente naturais, mas também motivadas pela ação humana. De acordo com Laczko e Aghazarm ${ }^{16}$, os processos naturais e as atividades humanas provocam esta diversidade de causas e a mudança ambiental. Desse modo, as mudanças climáticas e a degradação ambiental são dois fatores que vêm configurando um novo cenário para os deslocamentos humanos, havendo multicausalidade. Para eles ${ }^{17}$, a diversidade de causas da migração dificulta a identificação dos fatores ambientais como "fio condutor principal" da migração.

Conforme a $\mathrm{OIM}^{18}$, os fatores dos deslocamentos forçados podem ser naturais (terremotos, erupções vulcânicas, inundações etc.) ou antrópicos (aquecimento global, chuva ácida, poluição fluvial, acidentes industriais, testes nucleares, mega projetos de desenvolvimento, esgotamento de recursos ambientais, degradação ambiental etc.). Sendo assim, as mudanças climáticas e

\footnotetext{
${ }^{14}$ BINGHAM, John. Priorizando Necessidades: uma abordagem baseada em direitos para as Migrações Mistas, p. 43.

${ }^{15}$ ONU - ACNUR. ACNUR promove debate em Brasília sobre deslocamentos forçados por questões ambientais.

${ }^{16}$ AGHAZARM, LACZKO, op. cit., p. 46.

17 Ibidem, p. 17.

${ }^{18}$ OIM: International Organization for Migration. Environmentally-Induced Population Displacements and Environmental Impacts Resulting from Mass Migrations, p. 10.
} 
a degradação ambiental são geradas e agravadas por causas naturais e antrópicas, ocasionando deslocamentos ambientais.

As causas naturais, como furacões, tsunamis, enchentes (embora estas também possam ter causas antrópicas), secas, erosão do solo e desertificação (embora estas também possam ter causas antrópicas), por si só provocam um enorme desastre na terra. Sobre elas não se tem controle, pois a natureza muitas vezes tem reflexos inesperados e repentinos que o ser humano não pode dominar. Segundo a OIM ${ }^{19}$, catástrofes naturais causam destruição de casas, vilas, fazendas e empresas, culminando em deslocamento em massa de pessoas.

Além das causas naturais de catástrofes, há também causas antrópicas que ocasionam desastres ambientais e deslocamentos ambientais, como desertificação (que também pode possuir causa antrópica), desmatamentos, queimadas e construções. Para $\mathrm{Hens}^{20}$, por exemplo, o desmatamento elimina terras e meios de subsistência dos indivíduos, especialmente minorias étnicas mais vulneráveis. Outros exemplos são aquecimento global e derretimento das geleiras e desastres causados por acidentes industriais. Em suma, ações humanas também causam degradação ambiental e, portanto, deslocamento de pessoas.

Em se tratando das consequências, segundo Kälin e Scherepfer ${ }^{21}$, desastres naturais acentuam desigualdades pré-existentes e discriminação, marginalizando ainda mais pobres, mulheres solteiras, idosos, pessoas com deficiência ou portadores de HIV / AIDS e doenças crônicas, além de afetar os direitos das minorias ou povos indígenas.

Para quem permanece no país de origem, as consequências mais acentuadas são degradação do solo, perda da população e dificuldade para reerguer a economia local, sendo necessário readaptação às mudanças ocorridas no local de origem. A mudança é, algumas vezes, difícil, pois catástrofes naturais podem ser quase irreversíveis. Para Zetter ${ }^{22}$, a mudança climática também reduz recursos necessários para subsistência, como alimentos e água, gerando conflitos dentro do país.

De acordo com Afifi, Govil, Sakdapolrak e Warnerer, em geral, o "movimento como forma de adaptação [das mudanças climáticas] tem aumentado consideravelmente nos últimos 10 anos, particularmente de áreas rurais para urbanas $[\ldots] "$. Por isso, quando se deslocam para outro país, os deslocados

\footnotetext{
${ }^{19}$ IDEM. Migration, Climate..., op. cit., p. 3.

${ }^{20}$ HENS, op. cit., p. 3.

${ }^{21}$ KÄLIN, Walter; SCHEREPFER, Nina. Protecting People Crossing Borders in the Context of Climate Change Normative Gaps and Possible Approaches, p. 2.

${ }^{22}$ ZETTER, Roger. Legal and normative frameworks, p. 20.

${ }^{23}$ AFIFI, Tamer et alii. Climate change vulnerability and human mobility. Perspectives of refugees from the East and Horn of Africa, p. 40.
} 
ambientais encontram dificuldades ainda maiores, pois, apesar de saírem do local de origem para melhorar suas condições de vida, existe forte possibilidade de que eles passem por privações no país acolhedor. Muitas dificuldades são enfrentadas e direitos humanos são violados. Para Laczko e Aghazarm,

[o]s direitos humanos das vítimas de desastres não são suficientemente considerados. O acesso desigual à assistência, a discriminação na prestação de ajuda, a transferência forçada, a violência sexual e de gênero, a perda de documentação, o recrutamento de crianças para combate, o retorno inseguro ou involuntário ou reassentamento e questões de restituição de bens são apenas alguns problemas muitas vezes encontrados por aqueles afetados em consequências de desastres naturais ${ }^{24}$.

As situações dos deslocados ambientais nos países de acolhimento não são boas, como aduz Zetter ${ }^{25}$, referindo-se, particularmente, aos Estados de Gana, Kenia, Bangladesh, Vietnam e Etiópia, locais onde ocorreu sua pesquisa de campo: "[...] pessoas deslocadas à força por fatores ambientais estão sujeitos a violações de direitos humanos básicos da mesma forma que os refugiados e os deslocados internos", como se vê nos conflitos resultantes da escassez de água, por exemplo, no sertão nordestino brasileiro.

Desta forma, a segurança dos países acolhedores muitas vezes é atingida ${ }^{26}$. Mesmo que o Estado não se sinta diretamente ameaçado, podem ocorrer profundas modificações ambientais ou escassez de recursos naturais, criando conflitos interestatais, como consequência do deslocamento ambiental, pois, de acordo com Dannereuther ${ }^{27}$, pessoas forçadas ao deslocamento intensificam tensões étnicas ou de identidade de grupos no local de acolhimento. Conforme Barnett e Adger ${ }^{28}$, "[a] mudança climática [...] pode comprometer a segurança humana, reduzindo o acesso aos, e a qualidade dos recursos naturais importantes para sustentar a subsistência".

Além de possíveis conflitos nos casos em que não há partilha de uma mesma crença, etnia ou religião, há também conflitos por escassez de produtos de subsistência, como aduz Gleditsch, apud Zetter: "[m]as, igualmente, quando os migrantes invadem o território de outras pessoas que também podem ter recursos limitados, o potencial de violência também é elevado"29. De acordo com Ramirez et alii,

[...] o repentino e acentuado aumento da densidade populacional pode contribuir para aumentar a degradação ambiental nos territórios receptores

\footnotetext{
24 AGHAZARM, LACZKO, op. cit, p. 17.

25 ZETTER, op. cit., p. 2.

26 LE PRESTRE, op. cit., p. 195.

27 DANNREUTHER, Roland. International security: The contemporary agenda, p. 70.

${ }^{28}$ BARNETT, Jon; ADGER, W. Neil. Climate change, human security and violent conflict, p. 16.

29 ZETTER, op. cit., p. 20.
} 
de "refugiados ambientais", causando uma maior pressão antrópica sobre o meio ambiente. Nesse cenário, os conflitos socioambientais por uso da terra e por acesso aos recursos naturais cada vez mais escassos podem-se tornar inevitáveis, levando a crer que a questão dos "refugiados ambientais" não é apenas migratória, mas também de segurança internacional ${ }^{30}$.

Destarte, a ação antrópica e as mudanças naturais, conjuntamente, provocam deslocamento de pessoas. Mas, nem sempre os locais de acolhimento estão aptos a proteger e proporcionar condições de vida digna aos deslocados ambientais.

\section{Da proteção dos deslocados ambientais}

Observadas as causas e as consequências das mudanças climáticas e da degradação ambiental, o Acnur ${ }^{31}$ aduz que o aquecimento global leva a eventos climáticos extremos, como secas e inundações, provocando mais mobilidade humana. Por isso o IPCC, apud Leighton ${ }^{32}$, ressalta que as projeções dos impactos sociais causados por mudança ambiental e desastres naturais resultam em "[a] umento dos riscos de saúde devido a ondas de calor na Europa; poluição em larga escala em comunidades costeiras da América do Norte; secas e inundações na Ásia, e redução de segurança alimentar e desnutrição na África".

Diante deste quadro, entende-se que os deslocados ambientais precisam de proteção. Segundo o Acnur ${ }^{33}$, "[m]igração e deslocamento são tradicionais saídas para responder a crises, como conflitos e perseguição". Essas respostas também ocorrem para sobrevivência dos deslocados ambientais. De acordo com Laczko e Aghrazan ${ }^{34}$, a migração é, por vezes, uma estratégia positiva que famílias, indivíduos e, às vezes, comunidades inteiras usam para melhorar suas vidas e reduzir o risco e vulnerabilidade.

Visando à sobrevivência destes deslocados ambientais, eles precisam de proteção de seus direitos humanos mais básicos e essa premissa precisa ser absorvida pela sociedade internacional. As proteções jurídicas nacionais e internacionais desses deslocamentos humanos ambientais são fornecidas por Direito Internacional dos Direitos Humanos, Direito Humanitário Internacional e Princípios Orientadores de Deslocamento Interno, além da proteção nacional de cada país. Assim, o Acnur ${ }^{35}$ observa que

\footnotetext{
${ }^{30}$ RAMIREZ, Andrés et alii. Cadernos de Debates Refúgio, Migrações e Cidadania, p. 250.

${ }^{31}$ ONU - ACNUR. ACNUR e Mudança Ambiental - Proteção, Mitigação, Adaptação.

32 LEIGHTON, Michelle; SHEN, Xiaomeng; WARNER, Koko. Climate Change and Migration: Rethinking Policies for Adaptation and Disaster Risk Reduction, p. 2.

${ }^{33}$ ONU - ACNUR. ACNUR e Mudança Ambiental..., op. cit.

${ }^{34}$ AGHAZARM, LACZKO, op. cit., p. 429.

${ }^{35}$ ONU - ACNUR. UNHCR Global Report 2011: Somália.
} 
[a] maioria das mobilidades humanas devido às alterações climáticas é projetada para ocorrer dentro de fronteiras nacionais. Os princípios Orientadores em matéria de Deslocamento Interno reconhecem que as pessoas deslocadas têm direito a direitos humanos em seus países, incluindo proteção contra deslocamento forçado ou arbitrário. Contudo, pessoas que se deslocam através das fronteiras, apenas por razões ambientais, normalmente não gozam de proteção como refugiados nos termos da Convenção de 1951.

Os movimentos dentro de fronteiras são atualmente protegidos pelo Direito Internacional Humanitário (DIH), pelo Direito Internacional dos Direitos Humanos (DIDH) e pelos Princípios Orientadores sobre Deslocamento Interno. Já os movimentos através de fronteiras internacionais podem ser protegidos pelo $\mathrm{DIH}$, pelo DIDH, pelo Direito Internacional de Refugiados e por regimes de proteção subsidiária e temporária para pessoas fugindo ou deslocadas por conflitos armados. Contudo, não há proteção específica para deslocados ambientais. De acordo com Zetter ${ }^{36}$, do que quer que esses indivíduos que se deslocam por motivos ambientais sejam chamados, a falta de status legal continuará, a menos que haja mudança institucional fundamental e consideração dada ao desenvolvimento de instrumentos adequados e normas. Ainda, para Zetter ${ }^{37}$,

[u]m tema dominante do discurso baseado em direitos é que os direitos não devem ser violados pelo deslocamento. Há, portanto, bem estabelecidas, normas internacionais, regionais e nacionais de instrumentos jurídicos e convênios para proteger os direitos das pessoas deslocadas pelos conflitos, perseguições, catástrofes naturais e projetos de desenvolvimento. Assim é surpreendente que um quadro semelhante para proteger os direitos de pessoas forçadas ao deslocamento por causa da mudança climática induzida não exista.

No que tange aos Direitos Humanos, de acordo com Laczko e Aghazarm ${ }^{38}$, a Declaração Universal dos Direitos Humanos de 1948

possui um quadro global para promover e proteger o direitos humanos [...]. Mas, desde aquela época, as organizações intergovernamentais e os governos nacionais têm pensado ser extremamente necessário estender e reforçar uma legislação para grupos ou categorias específicas de pessoas.

De acordo com Portela, o DIDH protege todos os indivíduos. Sendo ele universal, e também transnacional, é possível haver monitoramento internacional e responsabilização internacional dos Estados. Já o DIH, segundo Costa ${ }^{39}$,

\footnotetext{
${ }^{36}$ ZETTER, MORRIS, BOANO, op. cit.

${ }^{37}$ Ibidem, p. 1.

38 AGHAZARM, LACZKO, op. cit., p. 204.

${ }^{39}$ COSTA, Claudia Silvana da. Refugiados Ambientais, sujeitos em construção pelos efeitos das mudanças climáticas.
} 
é entendido em sentido amplo como o conjunto de direitos que protege as pessoas humanas em situação de conflito, sendo um dos mecanismos de amparo ao ser humano, ao lado do DIDH.

Compreende-se, então, que os deslocados ambientais serão também amparados por agências humanitárias, pois, conforme ressalta Portela ${ }^{40}$, existem casos de catástrofes que precisam da ação de agências humanitárias. Corroborando este pensamento, Costa ${ }^{41}$ defende que o DIH "[...] deve também responder e ser aplicado para o caso dos refugiados ambientais, que são igualmente vítimas dos efeitos provocados pelas alterações do clima e pelos impactos ambientais e sociais do planeta".

A partir da perspectiva da proteção aos deslocados internos ambientais, com relação às suas características, os Princípios Orientadores de Deslocamentos Internos, de acordo com IASC"2, "refletem princípios existentes do Direito Internacional dos Direitos Humanos e no Direito Humanitário Internacional. Um número crescente de Estados fez uso delas no desenvolvimento de leis ou políticas nacionais [...]". Contudo, estes princípios protegem os deslocados internos, mas eles são apenas recomendações, sem poder sancionador, ou seja, com pouca eficácia prática na proteção desses indivíduos.

No âmbito do RIR, a proteção destes indivíduos, segundo Ramirez et alii ${ }^{43}$, "consolidou-se, em perspectiva contemporânea e materializada em um complexo sistema normativo de Direito Internacional Público, a partir da vigência da Convenção de 1951, somada às disposições de seu Protocolo de 1967".

Sendo assim, os deslocados ambientais, por não possuírem temor bem fundado de perseguição ou ainda não sendo perseguidos por motivos de raça, religião, opinião política, grupo social e nacionalidade, e se nem sempre cruzarem a fronteira do território em que vivem, de acordo com Black ${ }^{44}$, não são "refugiado" convencional. Para Zetter ${ }^{45}$, o envolvimento do Acnur nestes casos de deslocamentos

[c]orreria o risco de diminuir a responsabilidade dos governos nacionais em relação aos seus próprios cidadãos, confundindo a necessidade de proteção dos refugiados e dificultando a função da agência central de proteger e ajudar refugiados 'tradicionais'. Mas, a experiência paralela do ACNUR com novas responsabilidades para com os deslocados sugere ser possível adaptações.

40 Ibidem; PORTELA, Paulo Henrique Gonçalves. Direito Internacional Público e Privado, p. 608.

${ }^{41}$ COSTA, op. cit.

42 IASC. Inter-agency Standing Committee (2008, 2-3).

${ }^{43}$ RAMIREZ et alii, op. cit., p. 221.

${ }^{44}$ BLACK, Richard. Environmental refugees: myth or reality?, p. 14.

${ }^{45}$ ZETTER, Roger. Environmentally displaced people: understanding the linkages between environmental change, livelihoods and forced migration, p. 10. 
Ainda, de acordo com Zetter ${ }^{46}$, o direito internacional dos refugiados não foi concebido para proteger pessoas deslocadas nas fronteiras por causa dos efeitos das mudanças climáticas, apesar deles fugirem de perigos específicos, como guerras por recursos naturais e, portanto, podendo encontrar-se em situação de refugiados.

Se o RIR não for ampliado por meio da Convenção de 1951, para que os deslocados ambientais possam ser uma categoria de pessoas protegidas por ele, uma articulação por parte dos Estados deve ser realizada.

A proposta de proteção de Zetter $^{47}$ seria uma medida mais eficaz para os deslocados ambientais por meio da cooperação internacional entre os Estados. Essas iniciativas políticas requerem diálogo de alto nível coordenado entre governos, organizações intergovernamentais e não governamentais. Concordando com tais medidas, Sparemberger e Vergani ${ }^{48}$ defendem que

[o]s Estados, possuem obrigações comuns de auxiliar aos povos afetados pelos efeitos das alterações climáticas, exigindo-se, no entanto, daqueles que, por meio de suas ações, tiveram um grau maior de participação na origem dos eventos que resultaram em deslocados, uma imputação diferenciada de atribuições [...].

Por tudo isso, de acordo com Ramirez et alii ${ }^{49}$, "Zetter afirma que uma proteção baseada em direitos como resposta ao deslocamento forçado é um princípio aceito e incutido na responsabilidade internacional dos Estados", embora os Estados possuam, muitas vezes, dificuldade de aceitar essa responsabilidade e de criar e implementar mecanismos para proteger os deslocados ambientais.

\section{Sugestões}

Portanto, é necessária cooperação interestatal eficaz na resolução de problemas internacionais, além de boa e responsável articulação entre os Estados e outros atores. Na cooperação internacional do RIR, Pacífico ${ }^{50}$ afirma que há a "existência de um impasse entre países do Norte com os do Sul, no qual se tem a falta de vontade dos Estados do Norte em dividir o fardo da proteção dos refugiados com os Estados do Sul que hospedam a esmagadora maioria dos refugiados do mundo". Para Betts ${ }^{51}$, esse impasse pode ser resolvido pelo Acnur via persuasão por cruzamento de assuntos.

\footnotetext{
46 Ibidem, p. 2.

47 Ibidem, p. 10.

${ }^{48}$ SPAREMBERGER, Raquel Fabiana Lopes e VERGANI, Vanessa. Migração, vulnerabilidade e (in) justiça ambiental: desafios e perspectivas, p. 142-143.

${ }^{49}$ RAMIREZ et alii, op. cit., p. 160.

${ }^{50}$ PACÍfICO, Andrea Pacheco. Protection by Persuasion: International Cooperation in the Refugee Regime. By Alexander Betts, p. 422.

51 BETTS, Alexander. Protection by Persuasion, p. 20.
} 
Para facilitar as relações entre os Estados, é preciso, para Betts ${ }^{52}$, que exista um elemento que "link" assuntos entre os Estado do Norte e os Estados do Sul. Desta forma, o Acnur poderia atrair os interesses dos Estados para que eles contribuissem com a proteção dos refugiados. Betts ${ }^{53}$ define a persuasão por cruzamento de assuntos como "as condições em que um ator A pode persuadir um ator $B$ que uma questão na área $X$ e outra questão na área $Y$ são ligadas como um meio para induzir o ator $B$ a agir na área $X$ nas bases de interesses na área $Y^{\prime \prime}$. Sobre isto, Pacífico $^{54}$ também ressalta que

Betts descreve "persuasão por cruzamento de questões", como as condições em que o ACNUR tem sido capaz de persuadir os países da proteção dos refugiados e outras conexões entre questões de outras áreas (migração, segurança, comércio, o desenvolvimento, ou a construção da paz), como um meio para induzir estados a contribuírem com a proteção.

Para resolução de um dilema entre atores internacionais, essa teoria de cooperação por cruzamento de assunto seria essencial, pois entre os deslocados ambientais também pode existir uma cooperação interestatal por meio da proteção por persuasão de Betts.

O impasse Norte-Sul, para Betts ${ }^{55}$, por exemplo, tem grandes consequências para os seres humanos que sofrem perseguições, não sendo, pois, diferente para os deslocados ambientais. Segundo Actas ${ }^{56}$, os Estados do Norte vêm poluindo o meio ambiente por meio das suas indústrias, contribuindo para que as mudanças climáticas se agravem cada vez mais. Destarte, países que emitem mais gases com efeito de estufa não são, em geral, os mais vulneráveis às alterações climáticas; pelo contrário, são menos vulneráveis do que os países em desenvolvimento ${ }^{57}$. Há aqui uma dicotomia que acentua a diferença Norte-Sul e, portanto, contribui para o fenômeno migratório.

Como na teoria de Betts, a grande maioria desses Estados situados no Norte não quer responsabilizar-se por certos assuntos, a menos que essas questões estejam inseridas em alguma área de interesse entre eles. Dessa forma, deve-se entender que é preciso cruzar assuntos na questão referente aos deslocados ambientais. Os atores que não querem cooperar devem ser persuadidos a tomar outra postura, de forma que, a partir de conferências, passem a proteger os deslocados ambientais.

\footnotetext{
${ }^{52}$ Ibidem, p. 176.

53 Ibidem, p. 4.

${ }^{54}$ PACÍ́FICO, op. cit., p. 423.

55 BETTS, Protection..., op. cit., p. 16.

${ }^{56}$ NUNES, Nuno. O papel das agências humanitárias no apoio aos refugiados e deslocados Ambientais, p. 38.

57 Ibidem, p. 40.
} 
Os Estados podem cooperar para proteger os deslocados a partir do cruzamento de questões via persuasão. Essas questões precisam estar ligadas para os Estados compartilharem suas obrigações relacionadas a questões como migrações e segurança. Dessa forma, atores não estatais (deslocados ambientais, sociedade civil, agências e órgãos não governamentais) podem persuadir atores estatais de que questões de degradação ambiental e mudanças climáticas e questões de segurança estatal são ligadas, como meio de induzir atores estatais a agir na área de degradação ambiental e mudanças climáticas com base no interesse estatal na área de segurança. Sendo assim, buscando segurança estatal, os Estados cooperarão e tomarão medidas nas áreas ambientais, melhorando, por fim, condições de vida e sobrevivência dos deslocados ambientais.

A sugestão de cooperação internacional com cruzamento de assuntos em áreas de interesse estatal se torna eficaz no caso dos deslocados ambientais, pois atinge o ponto chave, que é a segurança estatal. Considerando que os deslocados ambientais carecem de proteção pelo RIR, é necessário buscar cooperação interestatal ou entre Estados e outros atores internacionais, como o Acnur, para sua proteção.

\section{Referências bibliográficas}

AFIFI, Tamer; GOVIL, Radha; SAKDAPOLRAK, Patrick; WARNER, Koko. Climate change vulnerability and human mobility. Perspectives of refugees from the East and Horn of Africa. Institute for Environment and Human Security, Universidade das Nações Unidas, report n. 1, 2012.

AGHAZARM, Christine; LACZKO, Frank. Migration, environment and climate change: assessing the evidence. Geneva: International Organization for Migration, Institute for Environment and Human Security and United Nations University, 2009. Disponível em: <http://publications.iom.int/bookstore/free/migration_ and_environment.pdf >. Acesso em: 22 maio 2012.

AMMER, Margit; Boltzmann, LUDWIG. Climate change and Human Rights: The Status of Climate Refugees in Europe. Protecting Dignity: An Agenda for Human Rights. Report, June, 2009, p. 1-78.

BARNETT, Jon; ADGER, W. Neil. Climate change, human security and violent conflict. Political Geography, v. 26, 2007, p. 639-655.

BATES, Diane C. Ambiente de Refugiados? Classificando as Migrações Humanas Causadas pela Mudança de Ambiente. Population and Environment, v. 23, n. 5, maio 2002.

BETTS, Alexander. International Cooperation in the Global Refugee Regime. International Studies Association annual convention, 2008. Disponível em: <http://www.globaleconomicgovernance.org/sites/geg/files/Betts_GEG\%20 WP\%202008_44.pdf>. Acesso em: 20.12.2012. 
. Protection by Persuasion. New York: Cornell University, 2009.

BINGHAM, John. K. Priorizando Necessidades: uma abordagem baseada em direitos para as Migrações Mistas. Cadernos de Debates Refúgio, Migrações e Cidadania, v. 5, n. 5, Agosto 2010, p. 37-54.

BLACK, Richard. Environmental refugees: myth or reality? New Issues in Refugee Research, n. 34, March, 2001.

CASTLES, Stephen. Globalização, transnacionalismo e novos fluxos migratórios: Dos trabalhadores convidados às migrações globais. Lisboa: Fim de Século, 2005.

COSTA, Claudia Silvana da. Refugiados Ambientais, sujeitos em construção pelos efeitos das mudanças climáticas. Revista Fafibe Online. Disponível em: <http://www.unifafibe.com.br/revistasonline/arquivos/revistafafibeonline/ sumario/16/30032011213126.pdf >. Acesso em: 25 maio 2012.

DANNREUTHER, Roland. International security: The contemporary agenda. Cambridge: Polity, 2007.

HENS, Luc. Environmentally displaced people. Encyclopedia of Life Support Systems (EOLSS), v. 2, 2012, p. 48-51.

HUMAN Rights Education Associates - HREA. Refugiados. Disponível em: <http:// www.hrea.org/index.php?doc_id=511>. Acesso em: 21 maio 2012.

IASC - Inter-agency Standing Committee. Disponível em: <http://www. humanitarianinfo.org/iasc/pageloader.aspx?page= content-about-default $>$. Acesso em: 01 junho 2012.

KÄLIN, Walter; SCHEREPFER, Nina. Protecting People Crossing Borders in the Context of Climate Change Normative Gaps and Possible Approaches. Legal and protection policy research series, 2012. Disponível em: < http://www.unhcr. org/4f33f1729.pdf>. Acesso em: 11 junho 2012.

KRASNER, Stephen. International Regimes. Ithaca, NY: Cornell University Press, 1983.

LECKIE, Scott. Climate-related Disasters and Displacement: Homes for Lost Homes, Lands for Lost Lands. In GUZMÁN, José Miguel; MARTINE, George; MCGRANAHAN, Gordon; SCHENSUL, Daniel; TACOLI, Cecilia. Population Dynamics and Climate Change. Nova lorque: UNFPA; Londres: IIED, 2009, p. 119-132.

LEIGHTON, Michelle; SHEN, Xiaomeng; WARNER, Koko. Climate Change and Migration: Rethinking Policies for Adaptation and Disaster Risk Reduction. Studies of the University: Research, Counsel, Education, Publication Series of UNU-EHS, n. 15, 2011.

LE PRESTRE, Philippe. Ecopolítica Internacional. São Paulo: Senac, 2000.

NUNES, Nuno. O papel das agências humanitárias no apoio aos refugiados e deslocados Ambientais. Refugiados e Deslocados Ambientais: O Lado Humano das Alterações Climáticas. ACTAS, IX Congresso Internacional do CPR, Nov. 2010, p. 38-41.

OIM: International Organization for Migration. Discussion Note: Migration and the environment. Ninety-fourth session, MC/INF/288. 1 November 2007, p. 
1-9. Disponível em: <http://www.iom.int/jahia/webdav/shared/shared/mainsite/ about_iom/en/council/94/MC_INF_288.pdf>. Acesso em: 25 maio 2012.

. Migration, Climate Changes and Environment. IOM-Policy Brief. May, 2009, p. 1-9. Disponível em: <http://www.egypt.iom.int/Doc/iom_policybrief_ en.pdf > . Acesso em: 04 junho 2012.

. Environmentally-Induced Population Displacements and Environmental Impacts Resulting from Mass Migrations. Geneva: IOM publications, April, 1996, p. 1-125.

ONU - ACNUR. ACNUR promove debate em Brasília sobre deslocamentos forçados por questões ambientais. Disponível em: < http://www.onu.org.br/acnur-promovedebate-em-brasilia-sobre-deslocamentos-forcados-por-questoes-ambientais/> . Acesso em: 22 maio 2012.

. ACNUR e Mudança Ambiental - Proteção, Mitigação, Adaptação. 2011. Disponível em: <http://www.acnur.org/t3/fileadmin/Documentos/portugues/ eventos/UNHCR_and_environmental_change.pdf?view=1>. Acesso em: $01 \mathrm{de}$ Junho de 2012.

. UNHCR Global Report 2011: Somália. Disponível em: <http://www. unhcr.org/4fc880a70.pdf>. Acesso em: 07 junho 2012.

PACífICO, Andrea Pacheco. Protection by Persuasion: International Cooperation in the Refugee Regime. By Alexander Betts. Journal of Refugee Studies, 24 de Fevereiro 2012, p. 422-424. Disponível em: <http://www.researchgate.net/ publication/229686918_1._Protection_by_Persuasion_International_Cooperation_ in the_Refugee_Regime._By_Alexander_Betts_in_the_Journal_of_Refugee_Studies _24_\%282\%29_2011_p._422-424>. Acesso em: 01 de Junho de 2012.

PORTELA, Paulo Henrique Gonçalves. Direito Internacional Público e Privado. Salvador: Jus Podivm, 2009.

RAMIREZ, Andrés et alii. Cadernos de Debates Refúgio, Migrações e Cidadania, v. 5, n. 5, nov. 2010.

SPAREMBERGER, Raquel Fabiana Lopes; VERGANI, Vanessa. Migração, vulnerabilidade e (in) justiça ambiental: desafios e perspectivas. Revista do Direito, v. 33, 2010, p. 130-147.

SILVA, João Carlos Jarochinski. A construção de um regime internacional para a imigração ilegal. Revista ponto e vírgula, n. 6, 2009, p. 171-182.

TEIXEIRA, Paula. Direitos humanos dos refugiados. Prismas: Dir., Pol. Publ. e Mundial, v. 6, n. 1, jan./jun. 2009, p. 15-34.

ZANONI, Anelise. Refugiados, apenas uma das denominações da crise global. Revista do Instituto Humanitas Unisinos, n. 362, Maio 2011. Disponível em: <http:// www.ihuonline.unisinos.br/index.php?option $=$ com_content\&view $=$ article\&id $=$ $3874 \&$ secao $=362>$. Acesso em: 22 maio 2012.

ZETTER, Roger. Legal and normative frameworks. Forced Migration Review. United Kingdom, Issue 31, October, 2008, p. 62-63. 
ZETTER, Roger; BOANO, Camillo; MORRIS, Tim. Environmentally Displaced People: Understanding the Linkages between Environmental change, livelihoods and forced migration. Forced Migration Policy Briefing 1, November, 2008. Oxford: RSC/ODID/University of Oxford.

\section{Abstract \\ Protection of the environmentally displaced in the International Regime of Refugees}

The displacement of people by environmental causes gives birth to discussions because of the absence of legal recognition and particular legal protection for this category of people. In this sense, this article examines the International Refugee Regime (IRR), conceptualizes environmentally displaced persons (EDP) and reflects on their lack of protection by the IRR. Then, it examines the causes and consequences of displacements and the forms of protection to EDPs, concluding that existing regimes do not offer them effective protection. A solution, according to Betts (2009), would be cooperation for protection by cross-issue persuasion of state interest, persuading states to cooperate in their own interests, as a response for the absence of effective protection to EDPs.

Keywords: Environmentally Displaced Persons, international protection, Refugee Regime.

Recebido para publicação em 28/08/2014.

Aceito para publicação em 06/11/2014.

Received for publication in August, $28^{\text {th }}, 2014$. Accepted for publication in November, 06 ${ }^{\text {th }}, 2014$.

ISSN impresso: 1980-8585

ISSN eletrônico: 2237-9843

http://dx.doi.org/10.1590/1980-85852503880004309 